\title{
NEW ECON FOR LIFE ACTUARIES
}

\author{
BY
}

Knut K. Aase and Svein-Arne Persson*

\begin{abstract}
In an editorial in ASTIN BULLETIN, Hans Bühlmann (2002) suggests it is time to change the teaching of life insurance theory towards the real life challenges of that industry. The following note is a response to this editorial. In Bergen we have partially taught the NUMAT, or the NUMeraire based Actuarial Teaching since the beginning of the 90's at the Norwegian School of Economics and Business Administration ( $\mathrm{NHH})$. In this short note we point out that there may be some practical problems when these principles are to be implemented.
\end{abstract}

\section{Actuarial Mathematics vs Financial Economics}

As recognized by Bühlmann the model used in Life Insurance Mathematics is built on the two elements: (i) mortality, and (ii) time value of money. This is, however, not sufficient to comprise a consistent pricing theory of a financial product, such as a private life insurance contract, a pension or an annuity. It is rather remarkable that mathematicians have, for more that 200 years, arrogantly (or more precisely, ignorantly) disregarded any economic principles in pricing such products (or any other insurance products for that matter). It should not come as a surprise that it is rather natural to use the economic theory of contracts to study - insurance contracts.

Financial pricing of life insurance contracts often starts by assuming the existence of a market of zero coupon bonds. The market price at time zero $B_{0}(t)$ of a default free unit discount bond maturing at the future time $t$ is typically given by the formula

$$
B_{0}(t)=E^{Q}\left\{e^{-\int_{0}^{t} r(s) d s}\right\}
$$

where $r(t)$ is the spot interest rate process, and $Q$ is a risk adjusted probability measure equivalent to the originally given probability $P$. Standard references such as Heath, Jarrow, and Morton (1992) or Duffie (2001) show that most popular term structure models lead to this representation of the market price of a unit disount bond.

1 In addition to the response from Hans Bühlmann, the authors appreciate the comments from Editor Andrew Cairns. 
Without going into further technical details regarding such models, let us consider some standard actuarial formulae for the most common life insurance contracts. We consider first the two building blocks for life and pension insurance regarding one life: pure endowment insurance and whole life insurance. We start with the former, stating that "one unit" is to be paid to the insured if he is alive at time $t$. Let ${ }_{t} p_{x}$ be the probability that a person of age $x$ shall still be alive after time $t$. That is, if $T_{x}$ represents the remaining life time of an $x$ year old representative insurance customer at the time of initiation of an insurance contract, then ${ }_{t} p_{x}=P\left(T_{x}>\mathrm{t}\right)$. In the traditional framework, the single premium for a pure endowment insurance is

$$
{ }_{t} E_{x}=e^{-\int_{0}^{t}\left(\delta+\mu_{x+s}\right) d s}={ }_{t} p_{x} e^{-\delta t},
$$

where $\delta$ is the "force of interest", or technical interest rate, and $\mu_{x}$ is the death rate of an $x$ year old insurance buyer. On the other hand, the above formula reads in the new language

$$
{ }_{t} E_{x}^{M}={ }_{t} p_{x} B_{0}(t),
$$

provided the mortality risk is "diversifiable", or uncorrelated with the financial risk and "unsystematic". The superscript $M$ will be used to indicate marked based valuation. Notice that the difference between (2) and (3) is how we value the "unit" at the inception of the contract.

The simplest way to show relation (3) is as follows: Let $I_{\left(T_{x}>t\right)}$ denote the indicator function of the event $\left(T_{x}>t\right)$, i.e., $I_{\left(T_{x}>t\right)}=1$ if $T_{x}>t$ and zero otherwise. Observe that $E\left(I_{\left(T_{x}>t\right)}\right)={ }_{t} p_{x}$.

By financial theory the market value of the above contract is

$$
{ }_{t} E_{x}^{M}=E^{Q}\left\{e^{-\int_{0}^{t} r(s) d s} I_{\left(T_{x}>t\right)}\right\},
$$

where $E^{Q}\{\cdot\}$ denotes the expectation under an equivalent martingale measure $Q$. The expectation under the measure $Q$ can alternatively be written

$$
E^{Q}\left\{e^{-\int_{0}^{t} r(s) d s} I_{\left(T_{x}>t\right)}\right\}=E\left\{\xi_{t} e^{-\int_{0}^{t} r(s) d s} I_{\left(T_{x}>t\right)}\right\},
$$

where $\xi_{t}$ is the "density" process, i.e., $\pi_{t}=\xi_{t} e^{-\int_{0}^{t} r(s) d s}$ is a state price. Under the stipulated conditions the state price depends only on market variables, in this case the interest rate process, and is thus independent of the random variable $T_{x}$. By this independence we get:

$$
E\left\{\xi_{t} e^{-\int_{0}^{t} r(s) d s} I_{\left(T_{x}>t\right)}\right\}=E\left\{\xi_{t} e^{-\int_{0}^{t} r(s) d s}\right\} E\left(I_{\left(T_{x}>t\right)}\right)=E^{Q}\left\{e^{-\int_{0}^{t} r(s) d s}\right\}{ }_{t} p_{x},
$$

the first equality follows from independence, the second from from properties of the probability measure $Q$. The result finally follows from expression (1). 
Turning to the other building block in life insurance, the whole life insurance contract, here "a unit" is payable upon death. The single premium is denoted by $\bar{A}_{x}$, and is given by the formula

$$
\bar{A}_{x}=1-\delta \int_{0}^{\infty}{ }_{t} p_{x} e^{-\delta t} d t
$$

in the traditional approach, while in the new approach it is given by

$$
\bar{A}_{x}^{M}=1+\int_{0}^{\infty}{ }_{t} p_{x} B_{0}^{\prime}(t) d t
$$

where $B_{0}^{\prime}(t)=\frac{\partial B_{0}(t)}{\partial(t)}$. Here the difference between (4) and (5) stems from how we compute time changes in the present value of the "unit" in the two different models. Again it is the difference in how we value the "unit" in a dynamic financial market based framework that matters.

From these two contracts all the other standard contracts could easily be developed. One example which we use below is term insurance, i.e., "a unit" is payable upon death, but only if death occurs before a given horizon $T$. The single premium $A_{x: \bar{T}}^{1}$ of the term insurance contract can be expressed as

$$
A_{x: \overline{T 1}}^{1}=\bar{A}_{x: \overline{T 1}}-e^{\delta T} p_{x},
$$

where $\bar{A}_{x: \overline{T \mid}}=1-\delta \int_{0}^{T}{ }_{t} p_{x} e^{-\delta t} d t$, is the single premium of the endowment insurance. In the new language this formula becomes

$$
A_{x: T 1}^{1, M}=\bar{A}_{x: \overline{T 1}}^{M}-B_{0}(T)_{T} p_{x}
$$

where $\bar{A}_{x: T 1}^{M}=1+\int_{0}^{T}{ }_{t} p_{x} B_{0}^{\prime}(t) d t$.

This approach would also be the starting point for valuing guarantees, and other financial derivatives that exist in this industry today. Other numeraires than the zero cupon bond would have to be considered as the contracts may be related to different portfolios of financial primitives.

The principles described above were indeed included in an elementary textbook in insurance mathematics (see ${ }^{1}$ Aase (1996)) already in the beginning of the 90's. At NHH this could be easily done, in the Humboltian tradition, since our program does not have any formal ties, or strings attached to the actuarial profession, and could e.g., ignore any legal aspects or accounting standards ${ }^{2}$.

This book is based on lecture notes from 1993.

2 Some universities have, in our view, a too close connection to the professional industry, which in some cases may actually hamper the natural development of the field. 


\section{POSSIBLE PROBLEMS WITH THE NEW APPROACH}

There are several scientific papers on the issues raised above ${ }^{3}$, but our aim is not to give a complete account of these here. We would, however, like to point out a few difficulties with the new approach.

First, the above price $B_{0}(t)$ could, according to Bühlmann (2002), "be read in today's newspaper". A quick look at the existing markets for bonds reveals that this is not possible, not even in highly liquid markets such as the UK Market, see e.g., Davis and Mataix-Pastor (2003). On the contrary, there is a serious "missing markets" problem, meaning that the complete term structure for maturities longer than 1 year must typically be extracted from only a small number (maybe not more than two or three) of bond prices.

The above formulae require, on the other hand, the functions $B_{0}(t)$ to be given for all $t$, and moreover, this should be possible at every instant, e.g., at every day, as time goes.

Even if this difficulty could be partially overcome technically, by smoothing the yield curve (see e.g., Adams and van Deventer (1994) or Cairns (1998)), the issuer of the insurance products would face a second problem, this time of a pedagogical nature: Identical and long term insurance contracts may obtain discernible different single premia on consecutive days, or even within the same day. This difference would thus be due to daily (or intra-daily!) fluctuations in the financial market, ceteris paribus. None of these issues arise in the traditional approach, which is based on a so-called technical interest rate, completely separated from real world financial market conditions.

Let us illustrate the latter problem here. We use term structure data for the Norwegian market ${ }^{4}$ from the first Friday of each month in 2002. Daily observations of the 1 year, 3 year, 5 year, and 10 year interest rates were available. These observations were interpolated to obtain the 2 year, 4 year, and the 6-9 year interest rates. Single premiums for a 10 year pure endowment and 10 year term insurance were calculated using the Norwegian N 1963 mortality table. The benefit is normalized to 100 .

Table 1 only reports monthly changes in single premiums, and thus, does not illustrate the potential problem of daily or even intra-daily price fluctuations. However, Table 1 does indicate that monthly price changes may vary from $0.47 \%$ to $3.44 \%$ for pure endowment single premiums. Actually, the average monthly change in the pure endowment single premium is $1.6 \%$. For term insurance the monthly changes in single premiums are less, from $0.02 \%$ to $1.87 \%$, with an average (over the 3 age groups) of the mean montly price change of $0.92 \%$.

The volatility of a financial asset is the (annualized) square root of the instantaneous variance of the logarithmic return. We estimated the volatilities

\footnotetext{
3 The authors have been involved e.g., in the following articles: See Persson (1998); Bacinello and Persson (2002) for pricing of life insurance under stochastic interest rates, Persson and Aase (1997); Miltersen and Persson (1999, 2003) for guarantees in life insurance, Miltersen and Persson (1999) also briefly discuss different numeraires.

4 Found at www.norges-bank.no.
} 
TABLE 1

\begin{tabular}{lcccccc}
\hline \hline Date & \multicolumn{3}{c}{ Pure endowment } & \multicolumn{3}{c}{ Term Insurance } \\
& 40 year & 60 year & 80 year & 40 year & 60 year & 80 year \\
\hline Jan 4, 02 & 52,26 & 42,36 & 9,90 & 3,09 & 16,00 & 62,25 \\
Feb 1, 02 & 52,02 & 42,16 & 9,85 & 3,06 & 15,82 & 61,53 \\
Mar 1, 02 & 51,39 & 41,65 & 9,73 & 3,04 & 15,72 & 61,19 \\
Apr 5, 02 & 50,38 & 40,84 & 9,54 & 3,02 & 15,63 & 61,02 \\
May 3, 02 & 50,01 & 40,53 & 9,47 & 2,99 & 15,49 & 60,49 \\
Jun 7, 02 & 48,94 & 39,67 & 9,27 & 2,95 & 15,25 & 59,67 \\
Jul 5, 02 & 49,87 & 40,42 & 9,45 & 2,98 & 15,41 & 60,17 \\
Aug 2, 02 & 51,58 & 41,81 & 9,77 & 3,03 & 15,70 & 61,05 \\
Sep 6, 02 & 53,16 & 43,08 & 10,07 & 3,09 & 15,98 & 61,95 \\
Oct 4, 02 & 52,86 & 42,84 & 10,01 & 3,08 & 15,96 & 61,93 \\
Nov 1, 02 & 52,56 & 42,60 & 9,96 & 3,09 & 15,97 & 62,05 \\
Dec 6, 02 & 53,46 & 43,33 & 10,13 & 3,12 & 16,15 & 62,63 \\
\hline \hline
\end{tabular}

Single premiums for pure endowment and term insurance contracts with benefit 100 and 10 years horizon for male insurance customer with age 40,60, and 80 years, respectively, at the inception of the contract. Single premiums are calculated by NUMAT as follows: Equation (3) is used for the pure endowment contract. For the term insurance contract we have discretized equation (7). First observe that $A_{x: \bar{T} \mid}^{1, M}=\int_{0}^{T} f_{x}(t) B_{0}(t) d t$ where $f_{x}(t)=\mu_{x+t} p_{x}$ represents the probability density of an x-year old person's remaining life time. Then $A_{x: \frac{M}{10} 1}^{1, M}$ is discretized as $\sum_{i=1 i-1}^{10} \mid q_{x} B_{0}(i)$, where $i-1 \mid q_{x}=\operatorname{Pr}\left(i-1<T_{x} \leq i\right)$ represents the probability of an x-year old customer to die in year $i$ after the contract is initiated. The single premiums are calculated using the prevailing term structure from the first Friday of each month in 2002 and the N 1963 mortality table.

of the same 6 contracts used as examples in Table 1, but now based on daily observations from 2002. The volatilities of all three pure endowment contracts are identical and equal to $6.73 \%$, which by the very nature of this contract is the same as the volatility of the 10 year bond. The volatility of the term insurance contracts are $3.47 \%, 3.45 \%$, and $2.76 \%$, for an insurance customer of age of 40,60 , and 80 years, respectively, at the inception of the contract. These volatilities are roughly of the same magnitude as the average of the volatilities of the 1-10 year bonds, estimated to $3.26 \%$ from the data.

Also notice that 10 years is a relative short horizon for a life insurance or pension contract. Both the problem of "missing markets" and of fluctuations of the single premiums are expected to be more severe for contracts with longer horizons.

\section{CONCLUSIONS}

We have pointed out that the approach of using financial market data to price life insurance and pension contracts may lead to substantial variations in the premiums charged. The variations are due to financial market volatility, rather than any differences in idiosyncratic risk. The data period we have picked is very normal, and one can easily envision substantially more discernable effects in more volatile times, and in financial markets in other countries of the world. 


\section{REFERENCES}

AASE, K.K. (1996) Anvendt sannsynlighetsteori: Forsikringsmatematikk (in Norwegian) (English: Applied probability theory: Insurance mathematics). Cappelen Akademisk Forlag, Oslo, Norge.

AdAms K. and van Deventer D. (1994) Fitting yield curves and forward rate curves with maximum smoothness. Journal of Fixed Income, 52-62.

Bacinello A. and Persson, S.-A. (2002) Design and pricing of equity-linked life insurance under stochastic interest rates. The Journal of Risk Finance 3(2), 6-21.

Bühlmann, H. (2002) New math for life actuaries. ASTIN Bulletin 32(2), 209-211.

CAIRNS, A.J.G. (1998) Descriptive bond-yield and forward rate models for the british government securities' market. British Actuarial Journal 4(2), 265-321.

Davis, M. and Mataix-Pastor, V. (2003) Finite-dimensional models of the yield curve. Working paper, Department of Mathematics, Imperial College, London SW7 2BZ, England.

Duffie, D. (2001) Dynamic Asset Pricing Theory. Princeton University Press, Princeton, New Jersey, USA, 3rd edition.

Heath, D., Jarrow, R. and Morton, A.J. (1992) Bond pricing and the term structure of interest rates: A new methodology for contingent claims valuation. Econometrica, 60(1) 77-105.

Miltersen, K.R. and Persson, S.-A. (1999) Pricing rate of return guarantees in a Heath-JarrowMorton framework. Insurance: Mathematics and Economics 25, 307-325.

Miltersen, K.R. and Persson, S.-A. (2003) Guaranteed investment contracts: Distributed and undistributed excess return. Scandinavian Actuarial Journal. Forthcoming.

Persson, S.-A. (1998) Stochastic interest rate in life insurance: The principle of equivalence revisited. Scandinavian Actuarial Journal, 97-112.

Persson, S.-A. and AASE, K. (1997) Valuation of the minimum guaranteed return embedded in life insurance contracts. Journal of Risk and Insurance 64, 599-617.

Knut K. Aase and Svein-Arne Persson

Norwegian School of Economics and Business Administration

5045 Bergen

Norway 